\title{
Analysis of Spectroscopic, Optical and Magnetic Behaviour of PVDF/PMMA Blend Embedded by Magnetite $\left(\mathrm{Fe}_{3} \mathrm{O}_{4}\right)$ Nanoparticles
}

\author{
Laila H. Gaabour \\ Department of Physics, College of Science, University of Jeddah, Jeddah, Saudi Arabia \\ Email: lhgaabour@uj.edu.sa
}

How to cite this paper: Gaabour, L.H. (2020) Analysis of Spectroscopic, Optical and Magnetic Behaviour of PVDF/PMMA Blend Embedded by Magnetite $\left(\mathrm{Fe}_{3} \mathrm{O}_{4}\right) \mathrm{Na}$ noparticles. Optics and Photonics Journal, 10, 197-209.

https://doi.org/10.4236/opj.2020.108021

Received: August 1, 2020

Accepted: August 28, 2020

Published: August 31, 2020

Copyright ( 2020 by author(s) and Scientific Research Publishing Inc. This work is licensed under the Creative Commons Attribution International License (CC BY 4.0).

http://creativecommons.org/licenses/by/4.0/

\section{(c) (i) Open Access}

\begin{abstract}
In the present work, magnetite $\left(\mathrm{Fe}_{3} \mathrm{O}_{4}\right)$ nanoparticles have been prepared by a simple chemical method. Polymer nanocomposites based on the blend between poly vinylamine fluoride (PVDF) and (methyl methacrylate) (PMMA) doped with different concentrations of $\mathrm{Fe}_{3} \mathrm{O}_{4}$ nanoparticles have been prepared. The structural, optical, and magnetization properties of the nanocomposite samples were studied using suitable techniques. The X-ray study reflected that the cubic spinal structure of pure $\mathrm{Fe}_{3} \mathrm{O}_{4}$ crystal. No small peaks or ripples were found in the $\mathrm{X}$-ray spectra, conforming to good dispersion of $\mathrm{Fe}_{3} \mathrm{O}_{4}$ within PVDF/PMMA matrices. The FT-IR analysis demonstrated the miscibility between the PVDF and PMMA blend with the interaction between the polymer blend and $\mathrm{Fe}_{3} \mathrm{O}_{4}$. The values of the band gap from UV-Vis study were decreased up to $4.21 \mathrm{eV}, 3.01 \mathrm{eV}$ for direct and indirect measurements, respectively. The magnetization was measured as a function of the applied magnetic field in the range of $-2000-2000$ Oersted. The curves of the magnetization indicated a paramagnetic behavior of pure $\mathrm{Fe}_{3} \mathrm{O}_{4}$ nanoparticles and PVDF/PMMA- $\mathrm{Fe}_{3} \mathrm{O}_{4}$ nanocomposites. The values of saturation magnetization for pure $\mathrm{Fe}_{3} \mathrm{O}_{4}$ are nearly $75 \mathrm{emu} / \mathrm{g}$, exhibiting a paramagnetic behavior, and it is decreased with the increase of $\mathrm{Fe}_{3} \mathrm{O}_{4}$ content.
\end{abstract}

\section{Keywords}

PVDF/PMMA Blend, Magnetite $\left(\mathrm{Fe}_{3} \mathrm{O}_{4}\right)$ Nanoparticles, XRD, FT-IR, UV-Vis Spectroscopy, Magnetization Properties

\section{Introduction}

Polyvinylidene fluoride (PVDF) is known as one of semi crystalline polymer [1] [2]. PVDF is characterized by its wide applications because of its excellent and 
extraordinary properties like smart mechanical strength, and high thermal stability [3] [4]. PVDF is a good response to the piezoelectric and pyroelectric properties. PVDF polymer has at least four polar phases known as $(\alpha)$ alpha, $(\beta)$ beta, $(\gamma)$ gamma, and $(\delta)$ delta phases. Due to the presence of these phases, PVDF is used to enhance and develop the electronic devices and sensors applications [5] [6]. Different pairs of polymer blends between PVDF and other polymers are examined by several authors, like PVDF/polyvinylpyrrolidone (PVP) [7] [8], PVDF/polyethylene glycol (PEG) [9] [10], PVDF/poly vinyl acetate [11], PVDF/polymethyl methacrylate (PMMA) [12] [13]. As an example of those blends, PMMA is considered one of the most interesting polymers because of its good compatibility with PVDF.

The changes in the structural and morphological PVDF/PMMA polymer blend prepared by different methods are studied by Kim et al. [14]. When PVDF/PMMA is prepared by melting technique, the reducing rate of crystallization after adding PMMA prefers the crystal phase formation and the phase formation is reduced. However, when PVDF/PMMA is prepared by the casting method, the addition of PMMA had little effect on the crystalline phases. However, Zhang et al. showed that the crystallization behaviour of the PVDF/PMMA blend is highly dependent on the components of mixed solutions [15]. They observed that the phases of PVDF are clear when the weight ratio of PVDF is higher than $30 \mathrm{wt} \%$ and the adding of $10 \mathrm{wt} \%$ of PMMA could help the growth of PVDF crystallization [16]. The PVDF/PMMA blend is thought to result from the interaction between the oxygen atom of the carbonyl groups in PMMA and the hydrogen atom in PVDF [17] [18].

Magnetite nanoparticles $\left(\mathrm{Fe}_{3} \mathrm{O}_{4}\right)$ have attracted increasing interest within the fields of applied nanoscience and technology attributed to their unique and new physicochemical properties that are achieved according to their particle size, shape morphology, and shape of geometric films. Various methods of preparation of magnetite nanoparticles were performed through several techniques, including co-precipitation showing that the addition of nanoparticles to the polymer and/or polymer blend may enhance compatibility between the polymers. Magnetite nanoparticles $\left(\mathrm{Fe}_{3} \mathrm{O}_{4}\right)$ are one of most nanoparticles to improve and enhance the magnetic properties for polymer nanocomposites in the industry [19] [20].

Pure blend without nanofiller between PVDF and PMMA blends have been prepared and investigated by FT-IR spectroscopy, X-ray, and thermal analysis [21] [22]. The nanocomposite sample $\mathrm{PVDF} / \mathrm{Fe}_{3} \mathrm{O}_{4}$ nanoparticles are synthesis by a simple ultrasonication method and investigated by XRD, SEM, DSC and VSM techniques [23]. Lan et al. [24] prepared a paramagnetic $\mathrm{PMMA} / \mathrm{Fe}_{3} \mathrm{O}_{4}$ nanocomposite and they observed high thermal stability and high saturation magnetization $\left(39 \mathrm{emu} \cdot \mathrm{g}^{-1}\right)$. The limits of our knowledge are that there is no PVDF/PMMA- $\mathrm{Fe}_{3} \mathrm{O}_{4}$ in literature, so, the target of the present work is to synthesise novel magnetite $\left(\mathrm{Fe}_{3} \mathrm{O}_{4}\right)$ nanoparticles and to evolve the nanocomposite films based on PVDF/PMMA loaded by different concentrations of $\mathrm{Fe}_{3} \mathrm{O}_{4}$. The spectroscopic, optical and magnetic properties of PVDF/PMMA- $\mathrm{Fe}_{3} \mathrm{O}_{4}$ nano- 
composites are characterized by different techniques. The nanocomposite films can be exploited for further magnetic applications.

\section{Experimental Work}

\subsection{Materials}

Polyvinylidene fluoride (PVDF) pellet has $M_{w}=1.8 \times 10^{4}$ with linear chemical structure $\left(-\mathrm{CH}_{2} \mathrm{CF}_{2}-\right)_{\mathrm{n}}$ and the polymethyl methacrylate (PMMA) with $M_{W}=1.2$ $\times 10^{5}$ were pouched from Sigma-Aldrich. All chemical to the synthesis of magnetite nanoparticles $\left(\mathrm{Fe}_{3} \mathrm{O}_{4}\right)$ such as Ferric chloride hexahydrate $\left(\mathrm{FeCl}_{3} \cdot 6 \mathrm{H}_{2} \mathrm{O}\right)$, ferrous chloride tetrahydrate $\left(\mathrm{FeCl}_{2} \cdot 4 \mathrm{H}_{2} \mathrm{O}\right)$, and ammonium hydroxide $\left(\mathrm{NH}_{4} \mathrm{OH}\right)$ were obtained from Sigma-Aldrich.

\subsection{Synthesis of Magnetite Nanoparticles $\left(\mathrm{Fe}_{3} \mathrm{O}_{4}\right)$}

The magnetite nanoparticles $\left(\mathrm{Fe}_{3} \mathrm{O}_{4}\right)$ were synthesized using the promising methods because of its simplicity and ease of implementation with less hazardous and fewer procedures. Ferric chloride $\left(\mathrm{FeCl}_{3} \cdot 6 \mathrm{H}_{2} \mathrm{O}\right)$ and ferrous chloride $\left(\mathrm{FeCl}_{2} \cdot 4 \mathrm{H}_{2} \mathrm{O}\right)$ were mixed using 2:1 molar ratio. The ferric solutions of both $\mathrm{Fe}^{2+}$ and $\mathrm{Fe}^{3+}$ were prepared by making their aqueous solutions in distilled water. Then the solutions were heated at $50^{\circ} \mathrm{C}$ for about $10 \mathrm{~min}$. After heating the solutions, it will be deposited in the presence of an ammonia solution $\left(\mathrm{NH}_{4} \mathrm{OH}\right)$ with constant stirring by the magnetic stirrer at $50^{\circ} \mathrm{C}$. It is also known that the nanocomposite polymeric solution is more stable when ammonium was added. Black color particles of magnetite nanoparticles are deposited. These nanoparticles are then separated from the solution using a strong magnet and washed several times with distilled water. Black magnetite deposits remain. The powder was then dried in a hot air oven at $100^{\circ} \mathrm{C}$ overnight. General reaction can be written as the following reaction:

$$
\mathrm{Fe}^{2+}+2 \mathrm{Fe}^{3+}+8 \mathrm{OH}^{-} \rightarrow \mathrm{Fe}_{3} \mathrm{O}_{4}+4 \mathrm{H}_{2} \mathrm{O}
$$

\subsection{Preparation of PVDF/PMMA-Fe ${ }_{3} \mathrm{O}_{4}$ Nanocomposite Films}

Polyvinylidene fluoride (PVDF) pellet $(4.0 \mathrm{~g} / 50 \mathrm{ml})$ and polymethyl methacrylate (PMMA) powder $(4.0 \mathrm{~g} / 50 \mathrm{ml})$ were dissolved individually in tetrahydrofuran (THF) as a common solvent for the polymers at $60^{\circ} \mathrm{C}$ Pure solution of PVDF/PMMA was mixed and it stirred using magnetic stirrer about 4 hours at the same temperature. We followed the methods of authors to prepare the polymer blend nanocomposites containing nanoparticles [25] [26]. The different contents $(0.0,0.4,0.8$ and $1.2 \mathrm{wt} \%)$ of magnetite nanoparticles $\left(\mathrm{Fe}_{3} \mathrm{O}_{4}\right)$ were mixed with the previously polymer solution for $10 \mathrm{~min}$. After that, the nanocomposite solutions ( $\mathrm{PVDF} / \mathrm{PMMA}-\mathrm{Fe}_{3} \mathrm{O}_{4}$ ) were immersed in an ultrasonic device to sonicate about $10 \mathrm{~min}$ and to ensure that the $\mathrm{Fe}_{3} \mathrm{O}_{4}$ nanoparticles were dispersed in the polymeric solution. The final solutions were cast in glass dishes and put the dishes in an oven for about 72 hours at $48^{\circ} \mathrm{C}$. The nanocomposites (PVDF/PMMA- $\mathrm{Fe}_{3} \mathrm{O}_{4}$ ) become a flexible-type freestanding polymeric film with 
thickness in the range of $100 \mu \mathrm{m}$. Scheme 1 shows the possible reaction using a chem draw program between PVDF+PMMA embedded by $\mathrm{Fe}_{3} \mathrm{O}_{4}$ to obtain the PVDF/PMMA- $\mathrm{Fe}_{3} \mathrm{O}_{4}$ nanocomposite films.

\subsection{Characterization Techniques}

The X-ray diffraction (XRD) of the nanocomposites films were carried out by PANalytical X'pert Pro MPD diffractometer with $\mathrm{Cu}-\mathrm{K} \alpha$ radiation $(\lambda=1.5406$ $\AA$ ) at operating voltage $15 \mathrm{kV}$ over the range of $2 \theta=5^{\circ}-80^{\circ}$. The complexation between nanocomposites (PVDF/PMMA- $\mathrm{Fe}_{3} \mathrm{O}_{4}$ ) was studied using Fourier transform infrared (FT-IR) spectroscopy (FTIR-430, Jascow, Japan) at wavenumber range of $4000 \mathrm{~cm}^{-1}-400 \mathrm{~cm}^{-1}$. The UV-Vis spectra were recorded by a spectrophotometer (V-570 UV/VIS/NIR, Jasco, Japan) in the frequency range of 190 to $1000 \mathrm{~nm}$. The magnetization curves of the PVDF/PMMA- $\mathrm{Fe}_{3} \mathrm{O}_{4}$ nanocomposite films were measured using VSM measurement at room temperature $\left(25^{\circ} \mathrm{C}\right)$.

\section{Results and Discussion}

\subsection{X-Ray Measurements}

The crystalline structure of PVDF/PMMA films doped with different contents $(0,0.4,0.8$ and $1.2 \mathrm{wt} \%)$ of magnetite nanoparticles $\left(\mathrm{Fe}_{3} \mathrm{O}_{4}\right)$ is recorded using $\mathrm{X}$-ray diffraction as shown in Figure 1. The main X-ray peaks of pure $\mathrm{Fe}_{3} \mathrm{O}_{4}$ powders are founded and inserted in Figure 1. The X-ray spectrum exhibited peaks corresponding to (220), (311), (400), (422), (511) and (440) [27] [28] are reflects to $\mathrm{Fe}_{3} \mathrm{O}_{4}$ crystal with the cubic spinal structure.

The X-ray diffraction measurements of PVDF/PMMA show the semicrystalline structure [29] as the hump and broad peak recorded at $2 \theta=18.38^{\circ}$ with a peak at $2 \theta=39.07^{\circ}$. From the spectra of PVDF/PMMA films, no ripples and/or small peaks are found, indicating that the $\mathrm{Fe}_{3} \mathrm{O}_{4}$ has a good distribution in PVDF/PMMA blend. The movement of the position for Bragg angles from $2 \theta=$ $18.38^{\circ}$ to $2 \theta=20.04^{\circ}$ are founded confirms that the crystal structure of $\mathrm{Fe}_{3} \mathrm{O}_{4}$ is altered by its inserted within PVDF/PMMA matrices. A small decrease in the hump at $18.38^{\circ}$ after adding the $\mathrm{Fe}_{3} \mathrm{O}_{4}$ is seen suggesting that the amorphicity increased. An increase of the hump causes an increase of the amorphous nature inside the nanocomposite films according to Hodge et al. method [30]. The interaction between the PVDF/PMMA blend and $\mathrm{Fe}_{3} \mathrm{O}_{4}$ causing a decrease in the degree of crystallinity of the films. This demonstrating that complexation between $\mathrm{Fe}_{3} \mathrm{O}_{4}$ and PVDF/PMMA takes place in the amorphous region [31]. The amorphous nature is responsible for the higher conductivity behavior of the prepared samples.

\subsection{FT-IR Analysis}

The FT-IR spectra of PVDF/PMMA blend doped different concentrations of $\mathrm{Fe}_{3} \mathrm{O}_{4}$ are shown in Figure 2. For pure PVDF, the absorption bands at 1404 and $1066 \mathrm{~cm}^{-1}$ are assigned to $\mathrm{CH}_{2}$ wagging mode. The absorption band at $1167 \mathrm{~cm}^{-1}$ 


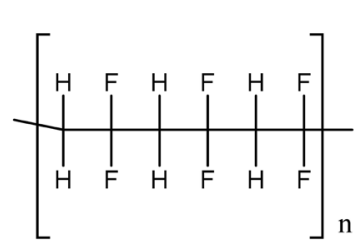

PVDF

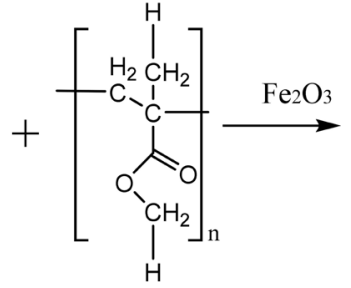

PMMA
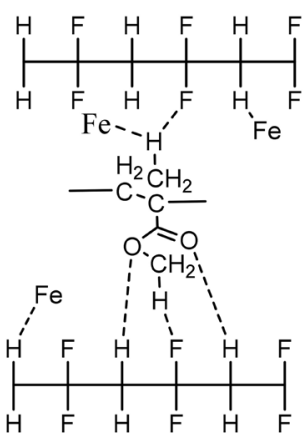

PVDF/PMMA - $\mathrm{Fe}_{2} \mathrm{O}$

Scheme 1. The possible reaction between PVDF + PMMA embedded by $\mathrm{Fe}_{3} \mathrm{O}_{4}$ to obtain the PVDF/PMMA- $\mathrm{Fe}_{3} \mathrm{O}_{4}$ samples.

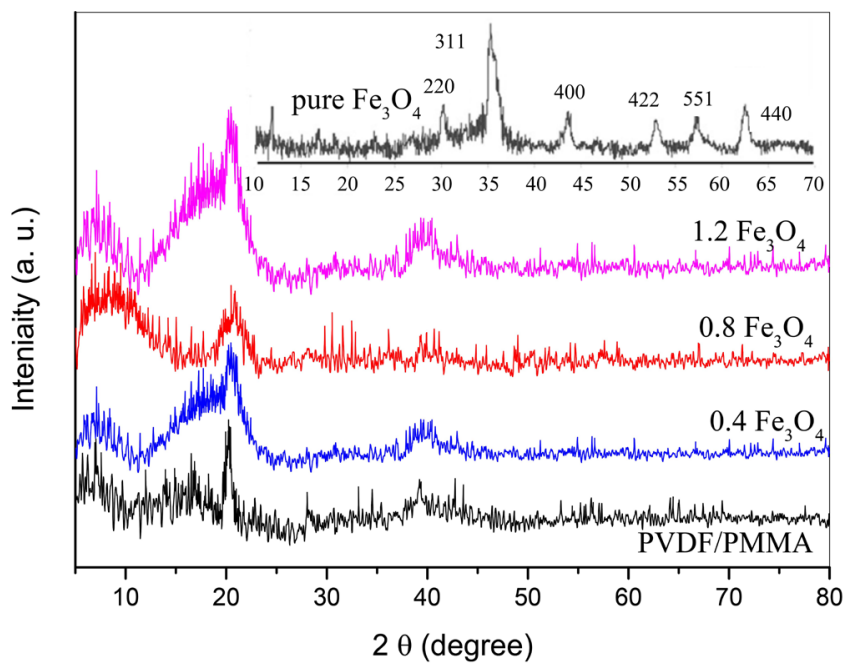

Figure 1. The X-ray diffraction of PVDF/PMMA films doped with different concentrations $(0,0.4,0.8$ and $1.2 \mathrm{wt} \%)$ of magnetite nanoparticles $\left(\mathrm{Fe}_{3} \mathrm{O}_{4}\right)$.

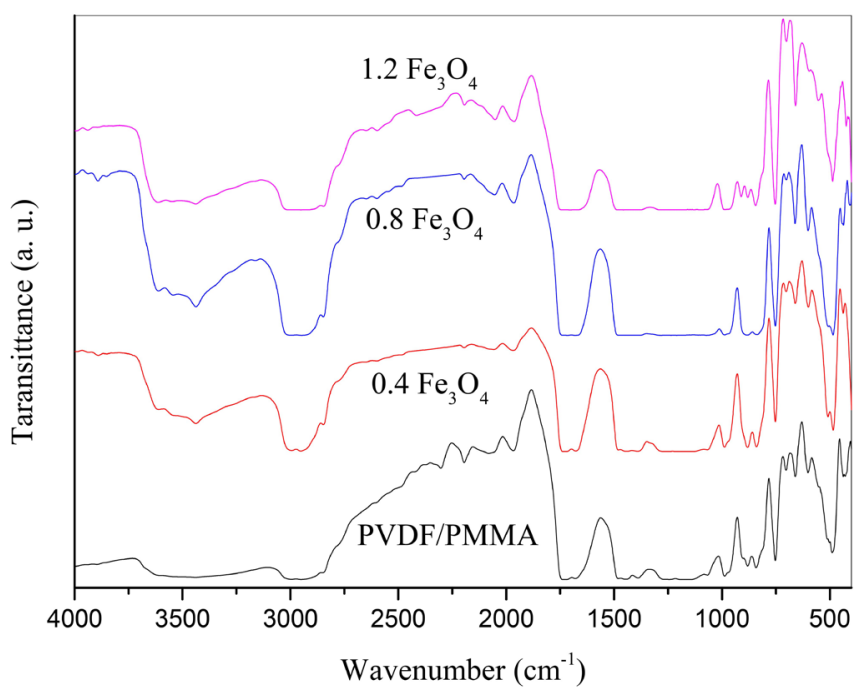

Figure 2. The FT-IR absorption spectra of PVDF/PMMA embedded with different concentration of magnetite nanoparticles $\left(\mathrm{Fe}_{3} \mathrm{O}_{4}\right)$. 
is assigned to $\mathrm{CF}_{2}$ asymmetric stretching mode since $\mathrm{CF}_{2}$ group is absorbed strongly in the region of $1120-1350 \mathrm{~cm}^{-1}$. The $\mathrm{C}-\mathrm{C}-\mathrm{C}$ asymmetrical stretching vibration band is observed at $880 \mathrm{~cm}^{-1}$. The absorption band at $796 \mathrm{~cm}^{-1}$ corresponds to $\mathrm{CF}_{2}$ skeletal vibration mode. The absorption band at $478 \mathrm{~cm}^{-1}$ corresponds to $\mathrm{CF}_{2}$ bending vibrational mode [32]. The assignments of FT-IR spectrum of PVDF have been reported as follows: $\alpha$-phase bands due to $\mathrm{CF}_{2}$ bending are observed at $482 \mathrm{~cm}^{-1}, 531 \mathrm{~cm}^{-1}$ and $615 \mathrm{~cm}^{-1}$. The main bands ascribed to $\mathrm{CH}_{2}$ wagging broad mode are observed at $1062 \mathrm{~cm}^{-1}$, whereas the $\beta$-phase band due to $\mathrm{CF}_{2}$ symmetric. The presence of the absorption band at $1729 \mathrm{~cm}^{-1}$ is attributable to the stretching of the carbonyl group of PMMA in the blend samples.

The FT-IR spectrum of pure magnetite nanoparticles is inserted inside Figure 2. For the magnetite, the band at $580 \mathrm{~cm}^{-1}$ corresponds to the vibration of the Fe-O bonds. Additionally, the bands at 1633 and $3400 \mathrm{~cm}^{-1}$ can be attributed to the stretching vibration of the hydroxyl groups on the surface of the magnetite nanoparticles [33]. The FT-IR spectra of the nanocomposite are found partially changed after the addition of $\mathrm{Fe}_{3} \mathrm{O}_{4}$ with a decrease or disappear of some IR bands. These results conform to an interaction between the $\mathrm{Fe}_{3} \mathrm{O}_{4}$ nanoparticle, and the polymer blend has occurred.

\subsection{UV-Vis Analysis}

Figure 3 depicts the UV-Vis absorption spectra of pure PVDF/PMMA polymer incorporated with the synthesis $\mathrm{Fe}_{3} \mathrm{O}_{4}$ nanoparticles. From the spectrum of pure $\mathrm{Fe}_{2} \mathrm{O}_{3}$ nanoparticles, the sharp absorption in the range of $200-400 \mathrm{~nm}$ in the UV region and weak absorption at $400-800 \mathrm{~nm}$ of the visible region is observed. The presence of the optical absorption of pure $\mathrm{Fe}_{2} \mathrm{O}_{3}$ nanoparticles occurs due to two types of electronic transmission mechanisms. The former is due to the contribution of the direct charge transition of $2 \mathrm{p}$ in $\left(\mathrm{O}_{2}\right.$-ions $) \rightarrow 3 \mathrm{~d}\left(\mathrm{Fe}^{3+}\right)$ in the UV absorption region, and the other originates from the indirect charge transition of $3 \mathrm{~d}\left(\mathrm{Fe}^{3+}\right) \rightarrow 3 \mathrm{~d}$ (visible absorption region.

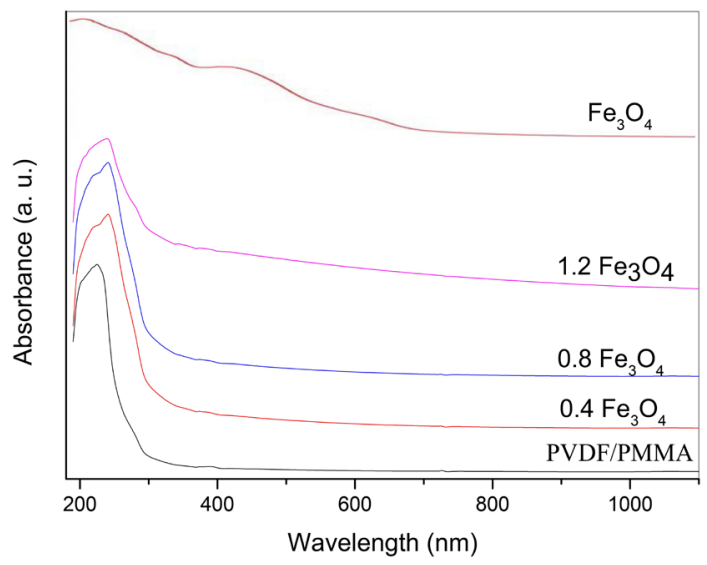

Figure 3. The UV-Vis absorption spectra of PVDF/PMMA embedded with different concentration of magnetite nanoparticles $\left(\mathrm{Fe}_{3} \mathrm{O}_{4}\right)$. 
The spectrum of pure PVDF/PMMA polymer blend shows an absorbance band at $219 \mathrm{~nm}$ attributed to the $\mathrm{n} \rightarrow \pi^{*}$ transition. Moreover, the spectrum displays the sharp edge which towards to red shifted from $219 \mathrm{~nm}$ to $241 \mathrm{~nm}$ as an increase of absorbance values for doped the films by the $\mathrm{Fe}_{2} \mathrm{O}_{3}$ nanoparticles, where the color of films is changed from the transparent color to pinkish red. These observations demonstrate that the link between the $\mathrm{Fe}_{2} \mathrm{O}_{3}$ nanoparticles with the functional groups in the PVDF/PMMA and caused a change of the band gap energy.

The estimated values of $E_{g}$ for PVDF/PMMA- $\mathrm{Fe}_{2} \mathrm{O}_{3}$ nanocomposite films can be determined by [34] [35] [36]:

$$
\alpha=\frac{B\left(h v-E_{g}\right)^{n}}{h v}
$$

where, $\alpha$ is the absorption coefficient, h $v$ is the photon energy, B is a constant. The values of $\mathrm{n}$ are equal to $1 / 2$ for allowed direct and it is equal to 2 for allowed indirect allowed transitions. The absorption coefficient $(\alpha)$ was determined from the equation: $\alpha=\frac{2.303 \times 10^{3} * A}{L}$, where $A$ is the absorption constant and $L$ is the sample thickness. Figure 4 and Figure 5 show the relation between $(\alpha h v)^{2}$ and $(\alpha h v)^{1 / 2}$ versus $h v$ of the PVDF/PMMA- $-\mathrm{Fe}_{2} \mathrm{O}_{3}$ samples. The portion of the straight line (dot lines in the figures) $s$ are an approach to zero absorbance gives values of $E_{g s}$ of direct and indirect transitions, respectively [37]. After doping $\mathrm{Fe}_{2} \mathrm{O}_{3}$ in pure polymer blend, the values of $E_{g s}$ are gradually decreased with the increase of $\mathrm{Fe}_{2} \mathrm{O}_{3}$ concentrations due to explained in terms of the formation of charge transfer complexes between the functional groups of PVDF/PMMA and the atoms of $\mathrm{Fe}_{2} \mathrm{O}_{3}$ [38]. The embedded $\mathrm{Fe}_{3} \mathrm{O}_{4}$ nanoparticles form an intermediate band among the PVDF/PMMA structures and thus decrease the band energy gap $\left(E_{g}\right)$ of nanocomposite films by absorbing the wavelength of lower energies. The values of the band gap of nanocomposite films decrease to $4.21 \mathrm{eV}$, $3.01 \mathrm{eV}$ as compared to $4.94 \mathrm{eV}$ and 4.50 from direct and indirect, respectively for pure PVDF/PMMA blend. The reduction of the values of the band gap energy is assumed to increase with a degree of disturbance to generate the localized state in the nanocomposites, as the incorporated of $\mathrm{Fe}_{2} \mathrm{O}_{3}$ produce energy levels in the band gap in the PVDF/PMMA matrix leading to decrease of the band gap energy. The estimated band-gap energy values of $\mathrm{Fe}_{2} \mathrm{O}_{3}$ are nearly $2.28 \mathrm{eV}$ and $2.1 \mathrm{eV}$ for allowed direct transition and allowed indirect transition, respectively. The values of $E_{g s}$ of $\mathrm{Fe}_{2} \mathrm{O}_{3}$ are slightly higher and blue shifted compared to the results of previous reports because of the quantum size confinement in the nanoparticles.

\subsection{Magnetic Analysis}

Figure 6 shows the magnetization $(\mathrm{emu} / \mathrm{g})$ of pure magnetite nanoparticles $\left(\mathrm{Fe}_{3} \mathrm{O}_{4}\right)$ and $0.4 ; 0.8$ and $1.2 \mathrm{wt} \%$ of $\mathrm{Fe}_{3} \mathrm{O}_{4}$ embedded in PVDF/PMMA polymer blend was measured as a function of the applied magnetic field $(\mathrm{Oe})$ in the range 


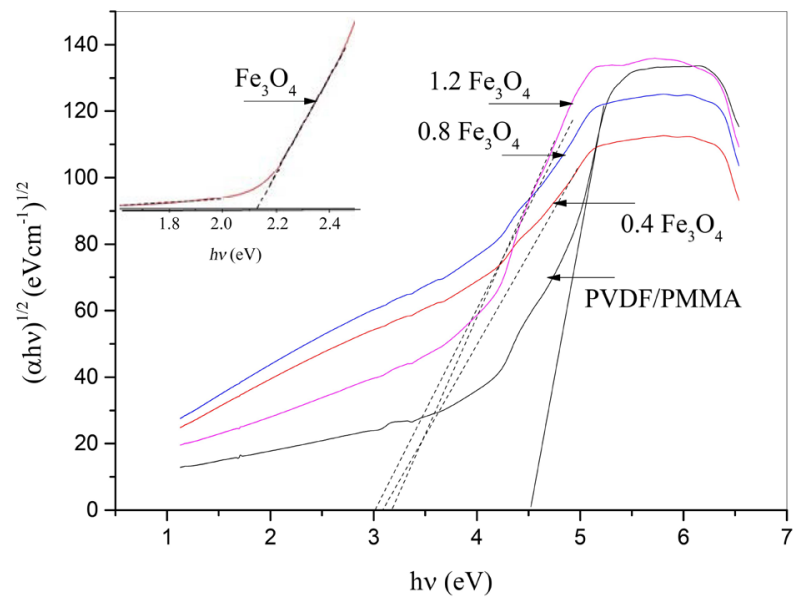

Figure 4. The relation between $(\alpha h v)^{1 / 2}$ and $\mathrm{h} v$ of PVDF/PMMA embedded with different concentration of magnetite nanoparticles $\left(\mathrm{Fe}_{3} \mathrm{O}_{4}\right)$ and the spectrum of pure $\mathrm{Fe}_{3} \mathrm{O}_{4}$ (insert the figure).

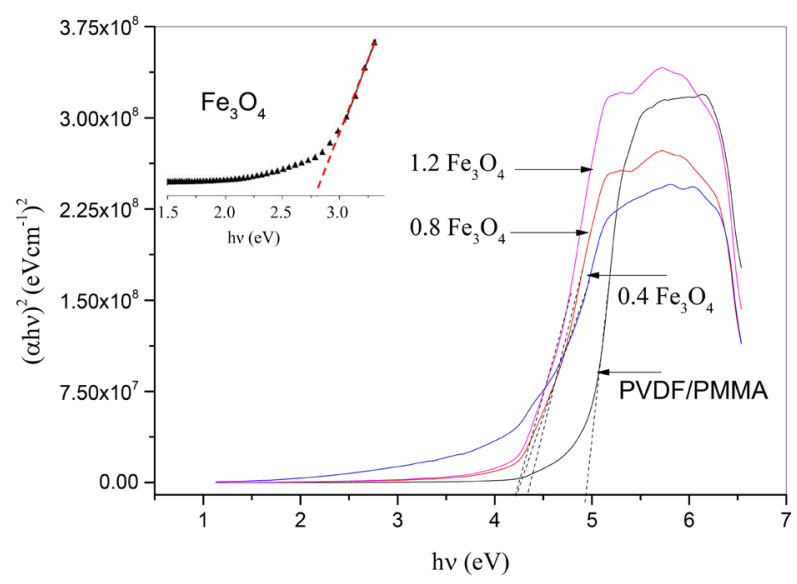

Figure 5. The relation between $(\alpha h v)^{2}$ and $h v$ of PVDF/PMMA embedded with different concentration of magnetite nanoparticles $\left(\mathrm{Fe}_{3} \mathrm{O}_{4}\right)$ and the spectrum of pure $\mathrm{Fe}_{3} \mathrm{O}_{4}$ (insert the figure).

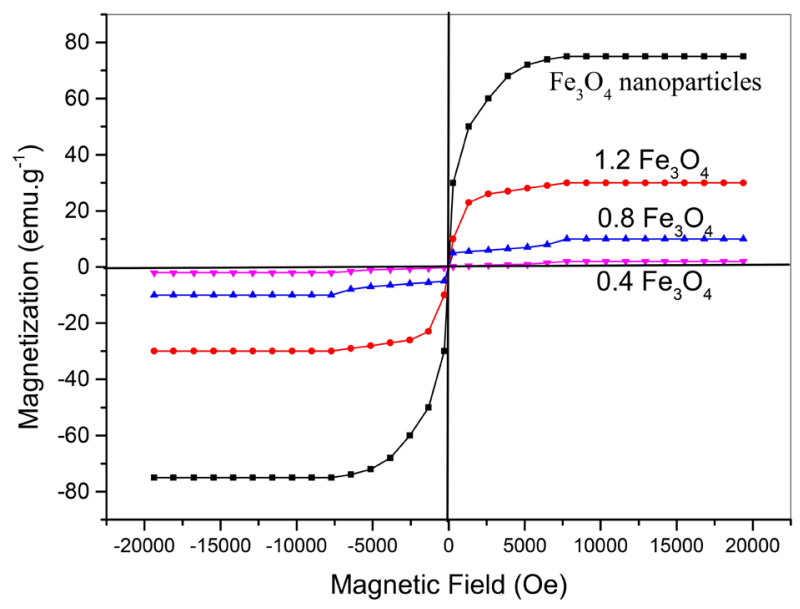

Figure 6. The magnetization curves of $\mathrm{Fe}_{3} \mathrm{O}_{4}$ and PVDF/PMMA embedded with $1.2,0.8$ and $0.4 \mathrm{wt} \%$ of magnetite nanoparticles $\left(\mathrm{Fe}_{3} \mathrm{O}_{4}\right)$. 
of (-2000 - 2000 Orested) at room temperature. The curves of the magnetization indicate a paramagnetic behaviour at room temperature for pure $\mathrm{Fe}_{3} \mathrm{O}_{4}$ nanoparticles and PVDF/PMMA- $\mathrm{Fe}_{3} \mathrm{O}_{4}$ nanocomposite films. No hysteresis loop from the magnetization curves is observed.

The values of saturation magnetization for pure $\mathrm{Fe}_{3} \mathrm{O}_{4}$ are nearly $75 \mathrm{emu} / \mathrm{g}$, exhibiting a paramagnetic behavior, and it is the decreased with decrease of $\mathrm{Fe}_{3} \mathrm{O}_{4}$ content embedded in PVDF/PMMA polymeric matrices as the following: $\approx 30$ emu/g for the sample 1.2 $\mathrm{Fe}_{3} \mathrm{O}_{4}-\mathrm{PVDF} / \mathrm{PMMA} ; 9.98 \mathrm{emu} / \mathrm{g}$ for the sample 0.8 $\mathrm{Fe}_{3} \mathrm{O}_{4}$-PVDF/PMMA and $4.98 \mathrm{emu} / \mathrm{g}$ for the sample $0.4 \mathrm{Fe}_{3} \mathrm{O}_{4}$-PVDF/PMMA. As expected, the magnetization of the PVDF/PMMA blend is near to zero value [39] [40] [41]. This is mainly because $\mathrm{Fe}_{3} \mathrm{O}_{4}$ nanoparticles are embedded into a nonmagnetic polymer matrix. With the decrease in the $\mathrm{Fe}_{3} \mathrm{O}_{4}$ content, the magnetic saturation value also decreases. These results suggest that the paramagnetic behavior observed in the nanocomposites arose from the magnetic $\mathrm{Fe}_{3} \mathrm{O}_{4}$ nanoparticles attributed to the decreasing tendency of the nanoparticles to aggregate on decreasing their content. Due to the magnetic properties of the prepared nanocomposites, the magnetic composite films can be further exploited for magnetic applications [42].

\section{Conclusion}

New nanocomposite films consist of PVDF/PMMA blend loaded by different concentrations of magnetite nanoparticles $\left(\mathrm{Fe}_{3} \mathrm{O}_{4}\right)$ using the casting method. The change of the structural, optical, magnetization properties of these nanocomposites has been studied in detail. The structural and chemical complexations between the components were characterized by XRD and FT-IR measurements. The X-ray spectra display the semicrystalline structure of all samples with a decrease of the crystalline degree as an increase of $\mathrm{Fe}_{3} \mathrm{O}_{4}$ contents. Further, the $\mathrm{X}$-ray spectrum exhibited some peaks that are reflected in the cubic spinal structure of the nanocomposites with good dispersion of $\mathrm{Fe}_{3} \mathrm{O}_{4}$ nanoparticles within PVDF/PMMA. The FT-IR spectra confirm the miscibility between the PVDF/PMMA blend and show the chemical interaction between the polymer blend and $\mathrm{Fe}_{3} \mathrm{O}_{4}$. From UV-Vis analysis, the embedded of $\mathrm{Fe}_{3} \mathrm{O}_{4}$ nanoparticles form an intermediate band inside PVDF/PMMA structures and causing a decrease of the band energy gap $\left(E_{g}\right)$. The magnetization was measured as a function of the applied magnetic field in the range of -2000 to 2000 Oersted at room temperature. The magnetization curves indicate a paramagnetic behavior of the $\mathrm{PVDF} / \mathrm{PMMA}-\mathrm{Fe}_{3} \mathrm{O}_{4}$. The values of saturation magnetization for pure $\mathrm{Fe}_{3} \mathrm{O}_{4}$ are nearly $75 \mathrm{emu} / \mathrm{g}$, exhibiting a paramagnetic behavior, and it is decreased with the decrease of $\mathrm{Fe}_{3} \mathrm{O}_{4}$ content. Due to the magnetic properties of the prepared nanocomposites, the films can be further exploited for magnetic applications.

\section{Conflicts of Interest}

The author declares no conflicts of interest regarding the publication of this paper. 


\section{References}

[1] Park, Y.J., Kang, Y.S. and Park, Y.S. (2005) Micropatterning of Semicrystalline Poly(Vinylidene Fluoride) (PVDF) Solutions. European Polymer Journal, 41, 1002-1012. https://doi.org/10.1016/j.eurpolymj.2004.11.022

[2] Hassen, A., Hanafy, T., El-Sayed, S. and Himanshu, A. (2011) Dielectric Relaxation And Alternating Current Conductivity of Polyvinylidene Fluoride Doped with Lanthanum Chloride. Journal of Applied Physics, 110, Article ID: 114119. https://doi.org/10.1063/1.3669396

[3] Elashmawi, I.S., Alatawi, N.S. and Elsayed, N.H. (2017) Preparation and Characterization of Polymer Nanocomposites Based on PVDF/PVC Doped with Graphene Nanoparticles. Results in Physics, 7, 636-640. https://doi.org/10.1016/j.rinp.2017.01.022

[4] Mohammed, M.I. (2018) Optical Properties of ZnO Nanoparticles Dispersed in PMMA/PVDF Blend. Journal of Molecular Structure, 1169, 9-17. https://doi.org/10.1016/j.molstruc.2018.05.024

[5] Gaur, A.M. and Rana, D.S. (2014) Structural, Optical and Electrical Properties of $\mathrm{MgCl}_{2}$ Doped Polyvinylidene Fluoride (PVDF) Composites. Journal of Materials Science: Materials in Electronics, 26, 1246-1251. https://doi.org/10.1007/s10854-014-2533-7

[6] Tawansi, A., Ayad, M.I.E. and Abdel-Razek, E.M. (1999) Effect of Valence Electron Spin Polarization on the Physical Properties of $\mathrm{CuCl}_{2}$-Filled Poly(Vinylidene Fluoride) as a Microwave Modulator. Journal of Applied Polymer Science, 72, 771-781. https://doi.org/10.1002/(SICI)1097-4628(19990509)72:6<771::AID-APP5>3.0.CO;2$\underline{\mathrm{O}}$

[7] Kim, W.S.H., Song, S., Lee, B.O., Kwon, K.H., Lim, Y.S. and Kim, M.S. (2002) Electrical Properties of PVdF/PVP Composite Filled with Carbon Nanotubes Prepared by Floating Catalyst Method. Macromolecular Research, 10, 253-258. https://doi.org/10.1007/BF03218314

[8] Jabbarnia, A., Khan, W.S., Ghazinezami, A. and Asmatulu, R. (2016) Investigating the Thermal, Mechanical, and Electrochemical Properties of PVDF/PVP Nanofibrous Membranes for Supercapacitor Applications. Journal of Applied Polymer Science, 133, 1-10. https://doi.org/10.1002/app.43707

[9] Zuo, D.Y., Xu, Y.Y., Xu, W.L. and Zou, H.T., (2008) The Influence of Peg Molecular Weight on Morphologies and Properties of PVDf Asymmetric Membranes. Chinese Journal of Polymer Science, 26, 405-414. https://doi.org/10.1142/S0256767908003072

[10] Wang, Y.P., Gao, X.H., Wang, R.M., Liu, H.G., Yang, C. and Xiong, Y.B. (2008) Effect of Functionalized Montmorillonite Addition on the Thermal Properties and Ionic Conductivity of PVDF-PEG Polymer Electrolyte. Reactive and Functional Polymers, 68, 1170-1177. https://doi.org/10.1016/j.reactfunctpolym.2008.04.002

[11] Chiu, F.C., Chuang, Y.C., Liao, S.J. and Chang, Y.H. (2018) Comparison of PVDF/PVAc/GNP and PVDF/PVAc/CNT Ternary Nanocomposites: Enhanced Thermal/Electrical Properties and Rigidity. Polymer Testing, 65, 197-205. https://doi.org/10.1016/j.polymertesting.2017.11.027

[12] Zhou, X. and Cakmak, M. (2007) Phase Behavior of Rapidly Quenched PVDF/PMMA Blends as Characterized by Raman Spectroscopy, X-Ray Diffraction and Thermal Techniques. Journal of Macromolecular Science, Part B-Physics, 46, 667-682. https://doi.org/10.1080/00222340701388680 
[13] Song, H., Yang, S., Sun and Zhang, H. (1013) Effect of Miscibility and Crystallization on the Mechanical Properties and Transparency of PVDF/PMMA Blends. Polymer-Plastics Technology and Engineering, 52, 221-227. https://doi.org/10.1080/03602559.2012.735314

[14] Kim, K.J., Cho, Y.J. and Kim, Y.H. (1995) Factors Determining the Formation of The $\beta$ Crystalline Phase of Poly(Vinylidene Fluoride) in Poly(Vinylidene Fluoride)-Poly(Methyl Methacrylate) Blends. Vibrational Spectroscopy, 9, 147-159. https://doi.org/10.1016/0924-2031(94)00092-U

[15] Ma, W., Zhang, J., Wang, X. and Wang, S. (2007) Effect of PMMA on Crystallization Behavior and Hydrophilicity of Poly(Vinylidene Fluoride)/Poly(Methyl Methacrylate) Blend Prepared in Semi-Dilute Solutions. Applied Surface Science, 253, 8377-8388. https://doi.org/10.1016/j.apsusc.2007.04.001

[16] Rajabzadeh, S., Maruyama, T., Ohmukai, Y., Sotani, T. and Matsuyama, H. (2009) Preparation of PVDF/PMMA Blend Hollow Fiber Membrane via Thermally Induced Phase Separation (TIPS) Method. Separation and Purification Technology, 66, 76-83. https://doi.org/10.1016/j.seppur.2008.11.021

[17] Kang, S.J., Park, Y.J., Bae, I., Kim, K.J., Kim, H.C., Bauer, S., Thomas, E.L. and Park, C. (2009) Printable Ferroelectric PVDF/PMMA Blend Films with Ultralow Roughness for Low Voltage Non-Volatile Polymer Memory. Advanced Functional Materials, 19, 2812-2818. https://doi.org/10.1002/adfm.200900589

[18] Sasaki, H, BalaH. P.K., Oshida and Ito, E. (1995) Miscibility of PVDF/PMMA Blends Examined by Crystallization Dynamics. Polymer, 36, 4805-4810. https://doi.org/10.1016/00323-8619(59)92967-

[19] Lin, C.R., Chu, Y.M. and Wang, S.C. (2006) Magnetic Properties of Magnetite Nanoparticles Prepared by Mechanochemical Reaction. Materials Letters, 60, 447-450. https://doi.org/10.1016/j.matlet.2005.09.009

[20] Huang, Y., Xiao, C. Huang, Q., Liu, H.L., Hao, J. and Song, L. (2018) Magnetic Field Induced Orderly Arrangement of $\mathrm{Fe}_{3} \mathrm{O}_{4} / \mathrm{GO}$ Composite Particles for Preparation of $\mathrm{Fe}_{3} \mathrm{O}_{4} / \mathrm{GO} / \mathrm{PVDF}$ Membrane. Journal of Membrane Science, 548, 184-193. https://doi.org/10.1016/j.memsci.2017.11.027

[21] Elashmawi, I.S. and Hakeem, N.A. (2008) Effect of PMMA Addition on Characterization and Morphology of PVDF. Polymer Engineering \& Science, 48, 895-901.

https://doi.org/10.1002/pen.21032

[22] Jarray, J., Larbi, F.B.C., Vanhulle, F., Dubault, A. and. Halary, J.L. (2003) Thermal and Mechanical Behavior of Amorphous and Semi-Crystalline Poly(Vinylidene Fluoride)/Poly(Methyl Methacrylate) Blends. Macromolecular Symposia, 198, 103-116. https://doi.org/10.1002/masy.200350810

[23] Bhatt, A.S., Bhat, D.K. and Santosh, M. (2011) Crystallinity, Conductivity, and Magnetic Properties of PVDF- $\mathrm{Fe}_{3} \mathrm{O}_{4}$ Composite Films. Journal of Applied Polymer Science, 119, 968-972. https://doi.org/10.1002/app.32796

[24] Lan, F., Liu, K.X., Jiang, W., Zeng, X.B., Wu, Y. and Gu, Z.W. (2011) Facile Synthesis of Monodisperse Superparamagnetic $\mathrm{Fe}_{3} \mathrm{O}_{4} / \mathrm{PMMA}$ Composite Nanospheres with High Magnetization. Nanotechnology, 22, Article ID: 225604. https://doi.org/10.1088/0957-4484/22/22/225604

[25] Gaabour, L.H. (2020) Effect of Selenium Oxide Nanofiller on the Structural, Thermal and Dielectric Properties of CMC/PVP Nanocomposites. Journal of Materials Research and Technology, 9, 4319-4325. https://doi.org/10.1016/j.jmrt.2020.02.057

[26] Gaabour, L.H. (2017) Spectroscopic and Thermal Analysis of Polyacrylamide/Chitosan (PAM/CS) Blend Loaded by Gold Nanoparticles. Results in Physics, 7, 2153-2158. 
https://doi.org/10.1016/j.rinp.2017.06.027

[27] Lu, W., Shen, Y., Xie, A. and Zhang, W. (2010) Green Synthesis and Characterization of Superparamagnetic $\mathrm{Fe}_{3} \mathrm{O}_{4}$ Nanoparticles. Journal of Magnetism and Magnetic Materials, 322, 1828-1833. https://doi.org/10.1016/j.jmmm.2009.12.035

[28] El Ghandoor, H., Zidan, H.M., Khalil, M.M.H. and Ismail, M.I.M. (2012) Synthesis and Some Physical Properties of Magnetite $\left(\mathrm{Fe}_{3} \mathrm{O}_{4}\right)$ Nanoparticles. International Journal of Electrochemical Science, 7, 5734-5745.

[29] Tripathi, S.K., Gupta, A. and Kumari, M. (2012) Studies on Electrical Conductivity and Dielectric Behaviour of PVDF-HFP-MMA-NaI Polymer Blend Electrolyte. Bulletin of Materials Science, 35, 969-975. https://doi.org/10.1007/s12034-012-0387-2

[30] Ramya, C.S., Selvasekarapandian, S., Savitha, T., Hirankumar, G., Baskaran, R., Bhuvaneswari, M.S. and Angelo, P.C. (2006) Conductivity and Thermal Behavior of Proton Conducting Polymer Electrolyte Based on Poly ( $N$-Vinyl Pyrrolidone). $E u$ ropean Polymer Journal, 42, 2672-2677. https://doi.org/10.1016/j.eurpolymj.2006.05.020

[31] Elashmawi, I.S., Abdelrazek, E.M., Hezma, A.M. and Rajeh, A. (2014) Modification and Development of Electrical and Magnetic Properties of PVA/PEO Incorporated with $\mathrm{MnCl}_{2}$. Physica B: Condensed Matter, 434, 57-63. https://doi.org/10.1016/j.physb.2013.10.038

[32] Chalkias, D.A., Giannopoulos, D.I., Kollia, E., Petala, A., Kostopoulos, V. and Papanicolaou, G.C. (2018) Preparation of Polyvinylpyrrolidone-Based Polymer Electrolytes and Their Application by In-Situ Gelation in Dye-Sensitized Solar Cells. Electrochimica Acta, 271, 632-640. https://doi.org/10.1016/j.electacta.2018.03.194

[33] Petcharoen, K. and Sirivat, A. (2012) Synthesis and Characterization of Magnetite Nanoparticles via the Chemical Co-Precipitation Method. Materials Science and Engineering: B, 177, 421-427. https://doi.org/10.1016/j.mseb.2012.01.003

[34] Patel, G., Sureshkumar, M.B. and Patel, P. (2015) Spectroscopic Investigation and Characterizations of PAM/PEO Blends Films. Soft, 4, 9-24.

https://doi.org/10.4236/soft.2015.42002

[35] Indolia, A.P. and Gaur, M.S. (2013) Optical Properties of Solution Grown PVDF-ZnO Nanocomposite Thin Films. Journal of Polymer Research, 20, Article No. 43. https://doi.org/10.1007/s10965-012-0043-y

[36] Rajeh, R., Morsi, M.A. and Elashmawi, I.S. (2019) Enhancement of Spectroscopic, Thermal, Electrical and Morphological Properties of Polyethylene Oxide/Carboxymethyl Cellulose Blends: Combined FT-IR/DFT. Vacuum, 159, 430-440. https://doi.org/10.1016/j.vacuum.2018.10.066

[37] Elashmawi, I.S., Hakeem, N.A. and Abdelrazek, E.M. (2008) Spectroscopic and Thermal Studies of PS/PVAc Blends. Physica B: Condensed Matter, 403, 3547-3552. https://doi.org/10.1016/j.physb.2008.05.024

[38] Elashmawi, I.S., Abdelrazek, E.M., Ragab, H.M. and Hakeem, N.A. (2010) Structural, Optical and Dielectric Behavior of PVDF Films Filled with Different Concentrations of Iodine. Physica B: Condensed Matter, 405, 94-98. https://doi.org/10.1016/j.physb.2009.08.037

[39] Goya, G.F., Berquó, T.S., Fonseca, F.C. and Morales, M.P. (2003) Static and Dynamic Magnetic Properties of Spherical Magnetite Nanoparticles. Journal of Applied Physics, 94, 3520-3528. https://doi.org/10.1063/1.1599959

[40] Dresco, P.A., Zaitsev, V.S., Gambino, R.J. and Chu, B. (1999) Preparation and Properties of Magnetite and Polymer Magnetite Nanoparticles. Langmuir, 15, 1945-1951. 
https://doi.org/10.1021/la980971g

[41] Majewski, P. and Thierry, B. (2007) Functionalized Magnetite Nanoparticles-Synthesis, Properties, and Bio-Applications. Critical Reviews in Solid State and Materials Sciences, 32, 203-215. https://doi.org/10.1080/10408430701776680

[42] Lu, A.H., Salabas, E.L. and Schüth, F. (2007) Magnetic Nanoparticles: Synthesis, Protection, Functionalization, and Application. Angewandte Chemie International Edition, 46, 1222-1244. https://doi.org/10.1002/anie.200602866 